\title{
POSTURAL SWAY IN ANKYLOSING SPONDYLITIS PATIENTS AND ITS CORRELATIONS: A CASE SERIES
}

\author{
Vitoria Emanuele Mendes ${ }^{1}$, Aline Cristina Carrasco², Mariana Felipe Silva ${ }^{1}$, Jefferson Rosa Cardoso ${ }^{1}$, Ligia Maria Facci ${ }^{1, \star}$ \\ 1.Universidade Estadual de Londrina, Londrina (PR), Brazil; 2.Universidade Estadual do Centro-Oeste, Guarapuava (PR), Brazil. \\ *Corresponding author: ligiafacci@hotmail.com
}

\section{BACKGROUND}

Different alterations in musculoskeletal system that occur in ankylosing spondylitis (AS) patients can lead to important postural control impairment, reflecting in their functional capacity. The objectives were to analyze the postural control of patients diagnosed with AS by the center of pressure (COP) variables, and its correlation with mobility, function, quality of life and fear of falling.

\section{METHODS}

Patients with clinical diagnosis of AS without age or gender restrictions were included. All patients were evaluated for mobility, functionality, quality of life and fear of falling through specific instruments. Static postural balance was measured by a portable force platform (Bertec Corporation). Data were collected in both visual conditions (eyes open and closed), and compare the bipedal and tandem support condition. Three attempts of 30 seconds were allowed for each participant on the force platform, with a 1-min interval between attempts.

\section{RESULTS}

Eight patients ( 5 women and 3 men), with a mean $(x)$ age of 46.7 years and a diagnosis time of 7.6 years, were evaluated. Most reported as main complaint and initial symptoms the pain in the hip (62.5\%), mean pain intensity $x=4.5 \mathrm{~cm}$ and time of morning stiffness of $x=75 \mathrm{~min}$. The patients had moderate mobility (BASMI) $(x=1)$ and functional impairment (BASFI) $(x=59.50)$, reduced quality of life (HAQ-S) $(x=1.35)$ and were afraid of falling (FES-I) $(x=38)$. When comparing the condition of eyes open with eyes closed, we found statistically significant differences in total mean velocity (TMV) in bipodal position ( $p=0.02$ ) and in all CoP measurements when patients were analyzed in tandem position $(p<0.05)$. A strong negative correlation was only found between the overall (OA) displacement $(\rho=-0.89)$ and mediolateral (ML) displacement $(\rho=-0.84)$ with the subject's functionality, evaluated by BASFI.

\section{CONCLUSION}

Patients with AS presented a deficit in postural control, which was higher in lower support postures and in the absence of visual information. It was found a strong negative relation with function and postural control, in other words, greater functionality, lower CoP areas and better balance.

\section{KEYWORDS}

Ankylosing spondylitis, Balance, Posturography. 